Interim Report

IR-05-036

\title{
On the Practical Limits to Substitution
}

Robert U. Ayres

(ayres@iiasa.ac.at / robert.ayres@insead.edu)

\section{Approved by}

Leen Hordijk

Director, International Institute for Applied Systems Analysis

July 28, 2005 


\section{Contents}

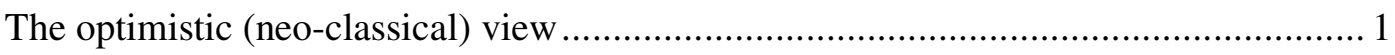

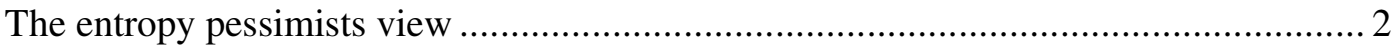

On the possibilities for substitution of natural functions ......................................... 2

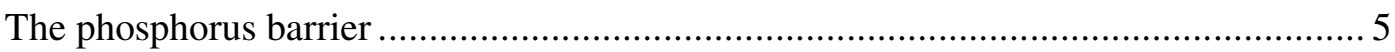

Scarcity vs Abundance: the geological perspective ................................................... 5

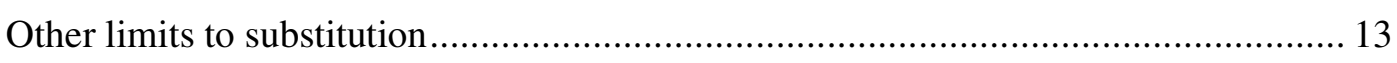

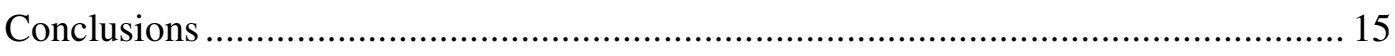

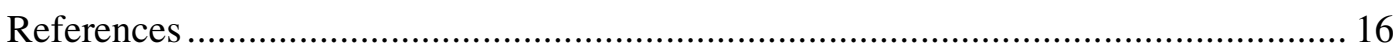




\section{Abstract}

This paper began as a commentary on a draft paper by Pezzey and Toman on the economics of sustainability (Pezzey and Toman 2002), although it has evolved considerably since then. The authors characterize economists' views on the potential for substitution of man-made capital for natural capital as a continuum between the strongly neoclassical positions of Solow and Weitzman, at one extreme and the 'entropy pessimists', notably Georgescu-Roegen and Daly, at the other. Solow has argued that man-made capital can, in principle, replace all natural capital except for unique places such as the Grand Canyon (Solow 1992). He has support from some scientists, such as Goeller and Weinberg, who argued (using mercury as an example) that there is a substitute for any and all scarce materials (Goeller and Weinberg 1976). On the other hand, the entropy pessimists and "strong sustainability" advocates in general, argue that the natural resource stock of fossil fuels - representing millions of years of accumulations of solar energy, as well as many natural ecological functions are irreplaceable. In the following, I will argue that both extremes are demonstrably inconsistent with both facts 'on the ground' and - in some particulars - with the laws of physics. Hence the debate - if any - should not be framed as a contest between the two extremes. There is room for debate, but I hope to show that it is considerably narrower. 


\section{About the Author}

Robert U. Ayres, Ph.D. in physics, currently Institute Scholar at IIASA, and Professor Emeritus at INSEAD. Author and co-author of 18 books and many articles and book chapters on technology, economics and environment. 


\title{
On the Practical Limits of Substitution
}

\author{
Robert U. Ayres
}

\section{The optimistic (neo-classical) view}

Economists have long tended to assume - basically for convenience - that every technology can be improved upon and every barrier can be surmounted (or broken through). This has been called "the age of substitutability" (Goeller and Weinberg 1976). The history of illumination illustrates the point beautifully (Nordhaus 1994). From torches dipped in animal fat to candles, oil lamps, kerosine lamps, gaslight, incandescent light, fluorescent light to light emitting diodes (LEDs) the series of substitutions seems endless.

It is but a short step to argue that the substitutability of capital for labor or resources is effectively unlimited. ${ }^{i}$ This position was emphasized and considerably hardened in the aftermath of the Club of Rome Report "Limits to Growth"(Meadows et al. 1972). The Solow paper "The economics or resources, or the resources of economics" (Solow 1974) demonstrated that, given a Cobb-Douglas production function with a factor representing natural capital, perpetual economic growth (of consumption) is possible provided that the elasticity of substitution of man-made capital and natural capital exceeds a certain minimum that depends on the rate of growth and the discount rate. Of course each of the factors (labor, and the two types of capital) are assumed to be expressed in monetary terms. The model does not allow for real materials with physical properties determined by molecular structure and elementary composition.

The mathematics of Solow's argument are impeccable but the underlying assumptions (i.e. the physics) are not. However, before I discuss the physics let me point out that in his response to Daly's critique (Daly 1997), Solow dismissed Daly's criticism with the comment that his simple model was not really intended to apply to an infinite time horizon, but only to a few generations, perhaps 60 or 70 years (Solow 1997). My response below to Solow's optimistic view is even applicable to a finite time horizon, albeit a somewhat longer one than Solow's, perhaps 200 years. During that time frame we can probably ignore such very long term possibilities as a new ice age, melting of the Greenland or Antarctic glaciersii, exhaustion of all fossil hydrocarbon resources, contact with intelligent alien life-forms or re-engineering the human genome.

I think it is reasonable to assume that the physical laws as we know them today, including the laws of thermodynamics (conservation of mass/energy, impossibility of perpetual motion machines), the impossibility of faster-than light travel, the impossibility of time travel, anti-gravity, teleportation and so on will remain valid during that period - and probably much longer. I also rule out Sunday Supplement possibilities such as cold fusion, surveillance microbots capable of flying like insects, 
and laser pistols with a kick like a Colt 44. The problem with the last two devices, beloved of science fiction writers, is energy storage and conversion. On the other hand, space travel within the solar system, solar satellites, lunar energy farms, solar sails, asteroid mining, and even L-5 colonies, are clearly within the realm of technological possibility.

\section{The entropy pessimists view}

The best-known pessimists (Georgescu-Roegen and Daly) point out that there is a second law of thermodynamics which says that entropy increases in every process and that perpetual motion machines are impossible. They are wrong to assert that this law implies that our civilization is totally dependent on a finite stock of high quality (low entropy) resources stored in the earth's crust. The fact that much of our industrial base currently utilizes fossil fuels and high quality metal ores is merely due to the ready availability of these resources at low cost. It does not follow from the entropy law that there are no substitutes.

The impossibility of perpetual motion does not ipso facto rule out unlimited recycling of scarce metals like platinum, for instance, as long as there is an adequate flux of available energy (exergy) (Bianciardi et al. 1993; Mayumi 1993; Ayres 1999). Entropy will continue to be produced, as it is now, but entropy is not a substance, still less is it harmful to health. The pessimist's argument that solar energy is too diffuse to be useful is clearly contradicted by the fact that photosynthetic organisms use it all the time. The argument that photovoltaic collectors necessarily require more energy to manufacture than they can capture is simply false; it was based on an early prototype long since superceded (Georgescu-Roegen 1993). The argument that only sunlight impinging on the earth's surface is available to us is also wrong. We can put solar collectors in satellites or on the moon, and we probably will do so.

The only part of the entropy pessimist thesis that stands up to scrutiny is the statement that we are currently using up stored low entropy resources, especially fossil fuels, much faster than they were originally produced. This is, however, an important observation because, while non-fuel sources of exergy are possible and are being developed, there are no known or plausible substitutes for fossil hydrocarbons or coal as chemical building blocks. It means that the pessimists are probably closer to the truth than the optimists, but for the wrong reasons, as I hope to show hereafter.

\section{On the possibilities for substitution of natural functions}

So the question is: given the properties of real materials and technologies, is it conceivable that man-made capital could replace all natural capital - including biospheric and ecological services - within the next two centuries? A slightly weaker question can be rephrased in the following way: within the next 200 years could we humans learn to 'terraform' (in the language of science fiction) a totally barren planet of the right mass and the right distance from a suitable star, given only solar energy, water and crustal rock of average composition? If the answer is 'yes', then Solow's optimistic view is not unreasonable. If the answer is 'no' then the unlimited substitution hypothesis is not tenable. I believe the answer is 'no'. Some reasons follow: 
(1) We humans also require an oxygen atmosphere. ${ }^{\text {iii }}$ Oxygen is too reactive for such an atmosphere to be naturally self-sustaining in the absence of plant life. The carbon-oxygen cycle on earth is currently not in balance. Oxygen is being consumed and free carbon is being oxidized. There is still plenty of free oxygen left (it accumulated for several hundred million years) but this imbalance would have to be corrected for long-term planetary sustainability. Otherwise we would have to produce oxygen electro-chemically and live under airtight domes, as any lunar colony would have to do.

The stocks of oxygen that took hundreds of millions of years to accumulate on earth in the first place could not be replaced, or created from scratch, much more quickly. The atmosphere is undoubtedly one of the most important of the 'low entropy' endowments we inherited from the past of the earth. To produce the amounts of free oxygen that we now consume annually without fossil fuels and plant life - i.e. from water or carbon dioxide - would require a process equivalent to biological photosynthesis and not much less efficient. The primary exergy required to drive the global economy amounts to only a small fraction (a little more than $0.01 \%$ ) of the total solar exergy impinging on the earth's surface. Biological photosynthesis efficiency varies from crop to crop, the highest being sugar cane and similar grasses (around 10\%), though the average is much less, perhaps $0.1 \%-0.5 \%$. Optimists note that photovoltaic (PV) cells already achieve up to $25 \%$ conversion efficiency and that the upper limit is certainly higher. On the other hand, the most efficient PV cells, such as dual junction thin films $(\mathrm{GaInP} 2 / \mathrm{GaAs})$ or triple junction $(\mathrm{GaInP} 2 / \mathrm{GaAs} / \mathrm{Ga})$ require extremely scarce elements, especially indium. Silicon cells seem to be limited to about $20 \%$ conversion efficiency.

But, unlike plants, PV cells are not self reproducing. Nobody can estimate the overall efficiency of a self-reproducing industrial system producing PV cells and using the electric power to drive all of the other essential manufacturing processes, including mining, purification, fabrication, construction (of panels and supports), electrical circuitry, electrolytic cells to produce hydrogen and oxygen, and synthesis of carbohydrates, fats and amino acids need for human nutrition. While it is said that modern PV cells can "pay for themselves" in terms of net energy output within a few years, such calculations do not take into account all the indirect downstream energy requirements of such an industrial system. ${ }^{\text {iv }}$

(2) As animals we also require considerable amounts of fresh drinking water, both for cooling and for metabolic waste disposal (via the kidneys). Plants - needed for oxygen production, as well as food - also require water for essentially the same reasons, plus the fact that water is essential for photosynthesis. Most industrial processes today also require large amounts of pure water, for a variety of purposes. Absent a colossal investment in desalination, or until all the plants and animals (except ourselves) can be genetically modified to be salt tolerant, a hydrological cycle is therefore essential.

A viable hydrological cycle absolutely requires, in turn, that average ambient temperatures remain above the freezing point and below the boiling point of water, over whatever portion of the earth is being utilized by plants and animals. If temperatures are too low the planet will freeze over (as has happened in the past.)

(3) We humans require a rather complex diet, consisting of proteins with an appropriate balance of amino acids, fats and carbohydrates ('major food groups') plus 
some trace minerals and vitamins - like vitamin $\mathrm{C}$ - not produced by the human body. It is not clear that we even know all of the essential compounds, and far from clear that all of them could be synthesized in a factory, except by utilizing biological organisms.

The synthesis of complex hydrocarbons from inorganic starting points is thermodynamically possible, but not simple. Carbon and hydrogen occur naturally in the earth's crust only in combination with other elements (especially oxygen). Fossil hydrocarbons, the only ones we know of, are derived entirely from accumulations of biomass in the distant past, transformed by anaerobic bacteria, heat and pressure. ${ }^{\mathrm{v}}$

The beauty of biological photosynthesis - known as the carboxylation cycle - is that it occurs almost reversibly at ambient temperature, and all molecules involved in the complex reactions are regenerated. Moreover, the photosynthesizing organisms plants, blue-green algae, etc. - also utilize the chemical energy captured from the light to reproduce themselves, which means manufacturing all of the necessary enzymes and intermediates. N.B. all biological energy metabolic processes involve the compounds adenosine triphosphate (ATP) and nicotinamide adenine dinucleotide phosphate (NADPH) to transfer light energy into chemical energy in the form of simple sugars. ${ }^{\mathrm{vi}}$ It is interesting that all of these compounds depend upon the element phosphorus, which is not biologically recycled as far as we know. ${ }^{\text {vii }}$

Given enough (and cheap enough) electric power we could separate hydrogen and oxygen from water by electrolysis, but apart from the carboxylation cycle, there is no known chemical process that breaks the carbon dioxide molecule (or any mineral containing carbon, such as a carbonate) yielding hydrocarbons or elemental carbon and oxygen. Such a process would be the reverse of combustion. It could conceivably be done only by electrolysis of liquid carbon dioxide, given unlimited electric power, but there is no data on such a process. It has never been attempted, as far as I can discover. In short, it is not at all clear that we (humans) could survive on a barren planet without plants. Plants are necessary, not only to close the carbon-oxygen cycle, but also to produce complex carbon-based molecules, such as simple sugars. Cellulose, fats and proteins are all constructed from simple building blocks produced only in green plants (not chemical plants).

Before moving on, I think it is important to realize that carbon fibers, which are becoming increasingly important components of so-called composite materials, are manufactured from synthetic fibers made initially from hydrocarbons. The process is a sophisticated modern version of the one Edison and Swan used in the 1880s to produce carbon filaments for the first incandescent lights, namely to pyrolize a cotton or other organic thread. Nobody knows how to produce pure elemental carbon in liquid (molten) form, still less how to contain or manipulate such a substance.

(4) Given that humans cannot survive indefinitely on earth without plants, average ambient temperatures cannot be much different from the present, if only because all plants (and animals) evolved to enjoy (and require) conditions not radically different from the present. Genetic adaptation is possible, but for large animals and long lived plants such as trees, natural adaptation takes many thousands or millions of years. Micro-organisms and insects, by contrast, adapt much more quickly. This inevitably alters the ecological balance between long-lived and short-lived species. The immediate consequence of warning will be that diseases and disease vectors will adapt much more quickly to new climatic conditions than domestic species or ourselves. 
(5) Apart from the need for a comfortable climate, we humans (lacking natural fur) also need clothing and shelter to survive in many local environments, except in caves. Clothing and shelter are necessarily produced from physical materials. These materials are currently obtained from plants, animals, minerals or 'synthetics' that are derived from fossil biomass, i.e. 'natural capital'.

It is true that sand and gravel, cement and glass could be produced on a barren planet (with tools and energy), and that man-made capital is involved in all of the extraction and processing activities. Man-made capital has significantly increased the productivity of the industrial system, and may yet increase the extent to which materials used for clothing and shelter can be reprocessed, thus extending their useful lives. However, while this can be regarded as 'substitution' at the margin, it has clear limits. The materials themselves, including so-called synthetic fibers, are mostly based on polymers of natural origin. As noted above, it would be difficult to produce most of them - except glass - from simple minerals. I do not quite believe in a world where everybody is wearing fiberglass clothes or none at all.

(6) Despite rapid and continuing progress in biochemistry, with very few exceptions, we are far from being able to understand and simulate complex biological processes even in a computer. To design a stable and self-adjusting artificial global ecosystem capable of surviving a variety of unpredictable conditions is very far beyond our present capabilities, and likely to remain so for many decades.

It follows that some form of agriculture based on sunlight, topsoil and rainfall is really essential, for the foreseeable future - probably much longer than 200 years. In other words, it is not possible, in principle, to replace the services of land and biomass with man-made capital, at least for a very long time to come.

\section{The phosphorus barrier}

All living organisms share an absolute need for phosphorus which is the essential ingredient of all biological energy metabolic processes, as noted above. There is no substitute for this element. Moreover, there is only one significant mineral source (apatite), which is a sedimentary rock of possibly marine origin. Once converted to fertilizer by treatment with sulfuric acid, and spread on the ground, soluble phosphates are quickly trapped in insoluble soil complexes. The phosphorus cannot be resolubilized except possibly by bacterial action.

It is true that there is probably enough phosphorus ore to last a couple of hundred years, given reasonable precautions. However, in the longer time frame, phosphorus scarcity is likely to be a serious problem. Development of genetically engineered organisms to recover insoluble forms of phosphorus could be an important long-term target of research.

\section{Scarcity vs Abundance: the geological perspective}

When economists talk about substitution of man-made capital for natural capital, they are implicitly making quite a strong assumption about technology, namely that raw material discovery, extraction and reduction costs (in real terms) will continue to fall in the future as they have in the past. Solow's 1974 model essentially projected that this process would continue forever (or at least through the multi-generation time horizon 
over which he claimed relevance). I will not comment on the prospects for more efficient extraction and processing. However, there is a lot to say about geological abundance.

Geologists classify elements as geochemically abundant and geochemically scarce. The first group consists of 12 elements, of which 4 are widely used metals (aluminum, iron, magnesium and manganese) that accounts for $99.23 \%$ of the mass of the earth's continental crust. Silicon, calcium, sodium, potassium, titanium and phosphorus are also in the top 12, though rarely used in metallic form. Only iron, among them, has an atomic weight greater than 40 . The other 90 or so known elements, including all other metals, altogether account for just $0.77 \%$ of the crustal mass. (A number of the transuranic elements, including plutonium, are not found in nature at all, but can only be synthesized in high energy physics laboratories.) The point is that all common rocks are composed of compounds of one or several of the abundant light elements. Hence it has appeared safe to assume [e.g. (McKelvey 1960)] that there is a standard (quasi-Gaussian) grade-abundance distribution, such that larger quantities of every element will be available at progressively lower grades, down to the crustal average.

For the geochemically scarce elements there are surprisingly different distributional patterns. Beryllium is an interesting example. It is not one of the scarcest elements, but although it is a component of something like 40 minerals, and 50 other minerals containing beryllium are known, yet only one (beryl) is found in (a very few) mineable deposits. Rubidium is another peculiar case: it is not a primary constituent of any known mineral. Yet rubidium is the $9^{\text {th }}$ most common metal and constitutes close to $0.31 \%$ of crustal mass.

On the other hand, scarcer elements are found in sizeable deposits at concentrations thousands of times greater than the crustal average. Examples include chromium $(0.2 \%$ of crustal mass); zinc $(0.132 \%$ of crustal mass); nickel $(0.08 \%)$, copper $(0.055 \%)$, tin $(0.040 \%)$ and lead $(0.016 \%)$. These metals, especially copper, are all currently mined in large tonnages.

The peculiarities of distribution are consequences of the earth's structure and the chemical characteristics of the elements. In the first place, heavier elements are naturally more concentrated in the core near the center of the earth, where they remain in a solid state under very high pressure. The solid (nickel-iron) core is surrounded by a semi-liquid mantle, on top of which floats a lighter solid crust made up of the lighter elements and their compounds. The geological system resembles a blast furnace in which molten metals fall to the bottom and the lighter slag floats on top.

The presence of heavy metals in the crust (analogous to slag), as distinguishable minerals - rather than atomic substitutes - usually reflects a magmatic intrusion from the molten mantle, resulting from some tectonic or volcanic disturbance. Mineral deposits are formed following such intrusions by differential cooling and crystallization, dissolution in super-heated brines which later penetrate and crystalize in cracks in the rock, and by chemical reactions with the crustal rock (Kesler 1994; Bachmann 1960). Other mechanisms for mineral formation and segregation on the earth's surface include differential weathering, differential deposition of weathered minerals, reactions with atmospheric gases, and biological activity. But the opportunities for scarce heavy elements to mineralize near the crustal surface are themselves very scarce. 
Only the naturally enriched minerals in the crust can be concentrated by conventional physical-chemical means. Mineral compounds of the scarcest elements do not exist, as such, in common crustal rocks such as granite or feldspar. Atoms of the very scarce elements are almost entirely distributed as atomic substitutes in minerals mainly oxides - of the more abundant light elements. These substitutions are not entirely random, of course, because they depend to some extent on the crystal structure of the 'parent' rock and the size and shape of the gaps that occur therein. For instance, lead is mostly an atomic substitute for potassium, while zinc is mainly an atomic substitute for magnesium.

Extraction of metals that are present only as atomic substitutes in other minerals is feasible only in a very few cases, mainly where they are contaminants that must be removed for other reasons. For example, antimony, arsenic, bismuth, cadmium, selenium, silver, tellurium and gold are all associated with lead, zinc and copper ores. Once the 'parent' minerals have been concentrated and smelted, it is feasible to separate and extract the other minor contaminants from slags or 'slimes' in secondary processes.

Taking the foregoing facts into consideration, it seems likely (though as yet unproven) that certain geochemically scarce elements tend to have a bimodal distribution (Figure 1), in which the smaller peak - corresponding to relatively high concentrations - reflects geochemical mineralization, while the main peak reflects atomic substitution in more common minerals, mainly silicates (Skinner 1976b, 1976a). ${ }^{\text {viii }}$ The implication is that certain metals - including some of the ones that have been industrially important for a very long time - may be effectively exhausted (for practical purposes) within a few decades (Committee on Mineral Resources and the Environment 1975). The fact that some predictions of early exhaustion have proved to be premature does not invalidate the fundamental argument.

Figure 1: Probable distribution of a geochemically scarce metal in the Earth's crust

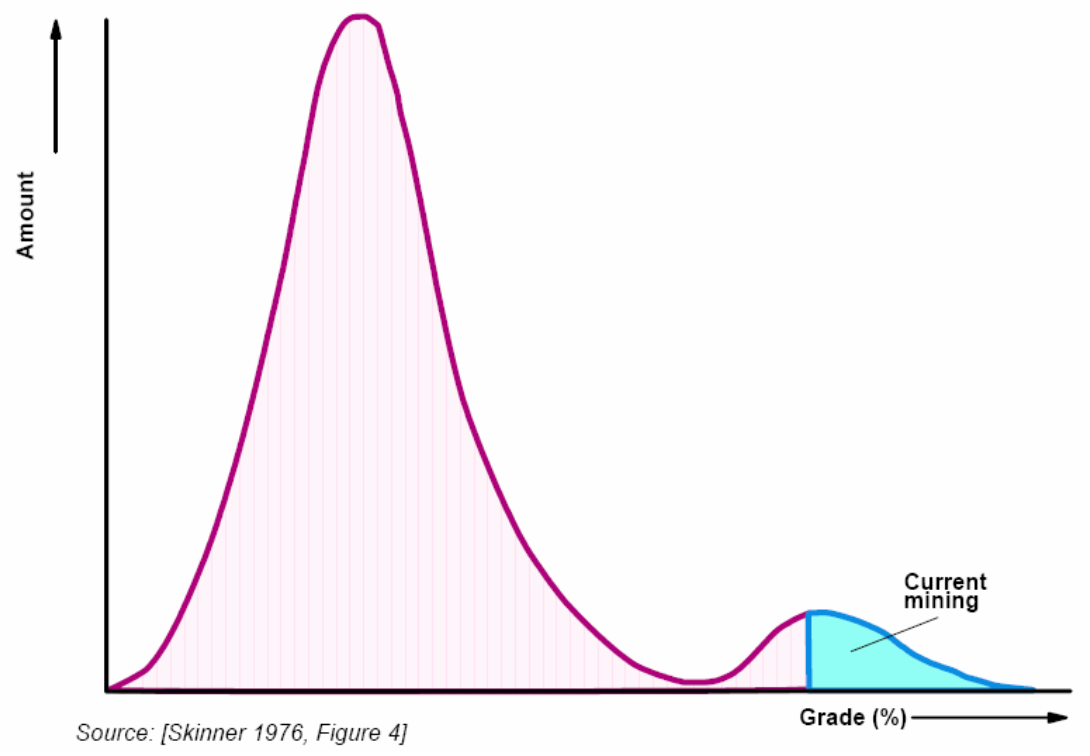


Copper and lead illustrate the problem. Copper from currently mined ores averages around $0.9 \%$ in grade globally $(0.5 \%$ in the U.S.), while $50-100$ Gigajoules (GJ) are required to produce a ton of pure metal from the ore, depending on the grade of ore and the age of the facilities. The exergy required for mining and concentration (to about $25 \% \mathrm{Cu}$ ) depends strongly on the grade of ore; current figures range from 11$15 \mathrm{GJ} / \mathrm{t}$ for underground mines and from 22.6-35.5 GJ/t for open pit mines [(Landner and Lindestrom 1999), Table 4.4 p.59]. Technological progress may reduce this figure still further, over time, but not by more than a factor of two or three. Meanwhile the ore grade will continue to decline, with predictable consequences ceteris paribus. The most advanced smelting and refining facilities today require as little as $10 \mathrm{GJ} / \mathrm{t}$ to convert concentrate to pure metal, and this figure is expected to drop soon to $7.3 \mathrm{GJ} / \mathrm{t}$ in one Swedish facility [op cit pp. 60-61]. However the relatively low energy requirement for copper smelting nowadays arises from more efficient exploitation of the heat energy released by the exothermic reaction between atmospheric oxygen and sulfide ores.

However, copper present as atomic substitutions in common crustal rocks has a grade of around $90 \mathrm{ppm}(0.009 \%)$ for basalt, $70 \mathrm{ppm}$ for black shale, $50 \mathrm{ppm}$ for shale, and $15 \mathrm{ppm}$ for granite and sandstone. The average is $60 \mathrm{ppm}$. Separating the copper atoms from the surrounding silicate matrix would require vastly more energy (exergy) than current processes. In other words, to mine the earth's crustal rock for copper, after the reserves of mineralized copper are exhausted, would increase energy requirements per ton by a factor of hundreds or even thousands (Skinner 1976b). This is called the 'mineralogical barrier' (Figure 2).

Figure 2: The mineralogical barrier

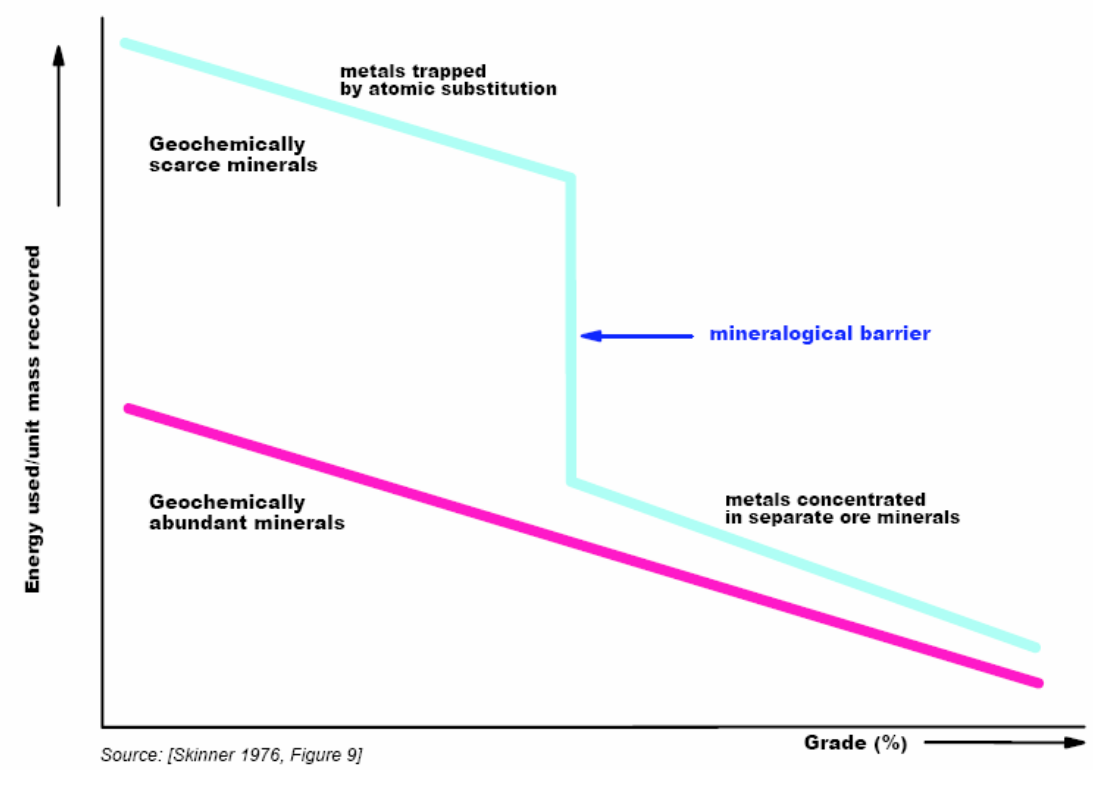

The case of lead is even more dramatic. Lead sulfide ores with a grade of $2 \%$ (and as high as 7\%) are being mined now, and barely $10 \mathrm{gJ}$ is needed to produce a ton of the pure metal from ore. However to obtain lead from atomic substitutions in crustal rock, where it has a grade of around $20 \mathrm{ppm}(0.002 \%)$ would require something like 400,000 GJ per ton, or 40 thousand times more than the current energy cost of lead. 
Even the most optimistic assessment of future exergy availability would necessarily exclude common rocks (or ocean water) as potential resources of these metals.

A similar situation may well apply to liquid and gaseous hydrocarbon resources, especially petroleum. There is an interesting background story. In 1956, based on prior work on mineral ore depletion in Europe by D. F. Hewett (1929), geologist M. K. Hubbert predicted that US petroleum production would peak between 10 and 15 years after the date of the prediction (Hubbert 1956). This prediction was made on the basis of a variety of data, including the fact that the rate of discovery of oil in the US (not including Alaska) had peaked in 1940 and declined sharply thereafter. In 1962 he refined his predictions, using additional data on discovery rates, reserves and production. He found that the rate of crude oil discoveries (including Alaska) had already peaked (in 1957), and that proved reserves were then at their peak (1962). Using a quantified version of Hewett's scheme, he predicted that peak production in the U.S. would occur in 1969. This proved to be accurate (the actual peak was 1970.) The Hubbert predictions were so disturbing to the oil industry that his methodology was very thoroughly criticized, in hopes of finding a flaw [e.g. (Menard 1981)]. However, no serious flaw in the logic was found, or ever has been.

Application of the Hubbert methodology to the global scene is relatively straightforward, except that the data are less reliable. However, the date of peak production is a function of the quantity of recoverable oil, which can remain as a variable. ${ }^{\text {ix }}$ Hubbert himself estimated, on the basis of data available in the late 1960s, that the upper limit of the quantity of recoverable oil in the world (including oil already produced) was between 1350 and 2100 billion barrels of oil (BBO). In that case global peak output would have occurred shortly before the year 2000 (Hubbert 1969).As it happens, his upper limit was a bit too pessimistic. A later study by the US Geological Survey (USGS), using another methodology (based on the distribution of known deposits in terms of specific gravity) concluded that cumulative world production to 1983 was 445 BBO, with demonstrated reserves of $723 \mathrm{BBO}$ and a $90 \%$ probability that undiscovered reserves would lie between 321 and 1417 BBO, with a 'most likely' value of $550 \mathrm{BBO}$ (Masters et al. 1983). That would correspond to a total ultimately recoverable quantity of $1718 \mathrm{BBO}$, well within Hubbert's earlier range.

As of late 1997 demonstrated world oil reserves were estimated at $1000 \mathrm{BBO}$, with another $550 \mathrm{BBO}$ expected to be discovered (most likely value). Total cumulative global consumption had already reached $800 \mathrm{BBO}$, for an ultimate total of $2350 \mathrm{BBO}$ (Hatfield 1997b). On this basis, the halfway point could be reached in the first decade of the present century, or early in the second decade, depending on political and economic factors. The most recent USGS assessment of world undiscovered oil actually raises the previous estimates by 20\% (United States Geological Survey World Energy Assessment Team 2000), citing two new promising regions for exploration, the Greenland shelf and offshore Suriname. (No oil has yet been produced from either region, however).

However, there are also plausible reasons to believe that the above is overoptimistic. First among them is that in the two years 1988-89 four Persian Gulf countries and Venezuela increased their demonstrated reserve estimates by a total of 277 BBO, without reporting any discoveries of new oil fields! This could only be justified on the basis of revised estimates of recoverability. But the chances are good that this reported increase was largely jockeying for influence within OPEC and for 
purposes of discouraging investment in alternative sources of energy (Campbell 1997). Another reason for skepticism is that production in the USSR, then the world's second largest producer, peaked in 1988. Several other countries have passed or are now approaching peak production (Figure 3). In consequence, the Middle East's share of total world output is necessarily increasing because no other region has the capability of increasing its oil output rate significantly.

Figure 3: Major Oil-Producing Countries: 1971-2001

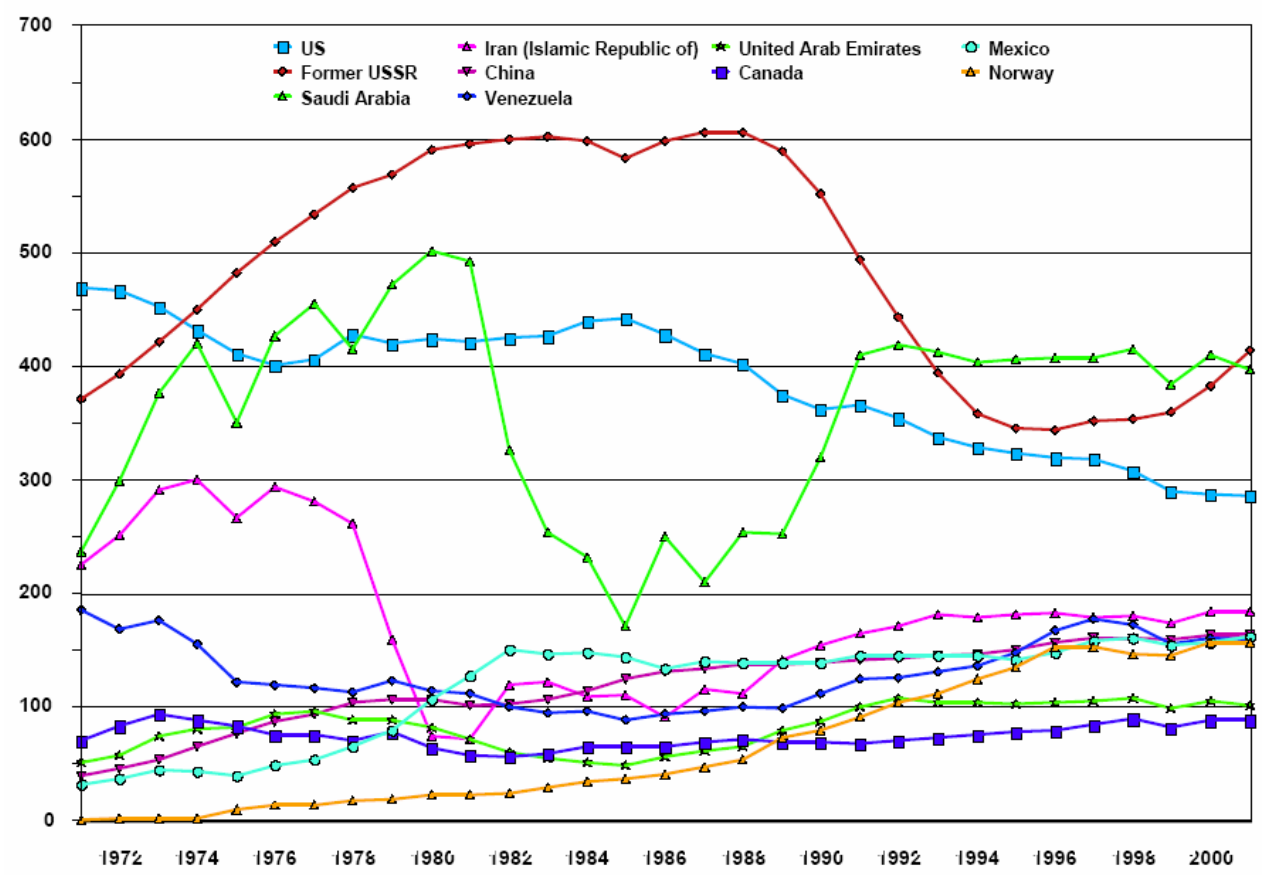

A third reason for believing that potential oil discoveries may have been overestimated for political or other reasons is that the global oil discovery rate has declined since the early 1960s, despite periods of high prices and intensive exploration. The optimism of a few years ago about the possibility of very large new 'supergiant' deposits under the Caspian Sea, or in Kazakhstan, has not yet been justified on the ground. More to the point, oil prices declined in the 1980s and early 90s because high prices at the beginning of the period stimulated investment in energy conservation (especially in Japan) and simultaneously stimulated exploration. Production capacity increased throughout the 1980 s to around $125 \%$ of consumption by 1990 (Hatfield 1997a). So prices declined. Then came the Iraqi attack on Kuwait, with the result that Iraq's 3 million bbl/day was subtracted from output, but slow growth in Japan and the US kept demand from exploding. Then the US recovery after 1992 and rapid economic growth in Asia, especially China, drove demand up sharply. Prices rose until the economic crisis in Southeast Asia (1996-97), cut back demand again. The current (2000) supply crunch was primarily the result of rapid economic recovery in Asia, combined with continued growth in the US and cyclic recovery in Europe. Details apart, the crunch was predicted (ibid).

The 'age of oil' is not yet ended, to be sure. Optimists were cheered by the latest USGS assessment of undiscovered world oil reserves, mentioned above, but the USGS 
methodology is open to serious challenge. For instance, when protocols for estimation of total resources via the Hubbert model and the USGS geologic analogy approach, using actual US data, it turns out that the Hubbert model overestimated based on experience through the 1930s, but underestimated from 1940 on, becoming increasingly accurate as production passed its peak in 1970. By contrast, the USGS model underestimated at the beginning, but overestimated dramatically from 1945 until well beyond the peak year and only approaches the right answer (from above) towards the end (Sterman et al. 1988). It seems likely that the USGS-2000 methodology still suffers from the same weakness.

Be that as it may, several independent lines of argument suggest that global peak production will occur near or soon after 2010 (Campbell and Laherrère 1998). Prices, on the other hand, are likely to continue to be unstable, but the long term trend will be up rather than down. Of course rising prices would eventually bring new sources into production, such as Greenland Shelf oil, Venezuelan heavy oil, Athabaska tar sands and Green River oil shale. The latter sources are potentially many times larger than the global stock of liquid petroleum. On the other hand they will be very much more expensive to extract and refine. Extremely large amounts of capital will be required. This creates a potential supply bottleneck, insofar as it may take a number of decades before new sources could reach the output levels of today. (Needless to say, the efficiency of recovery of usable liquid fuels will be significantly lower and the exergy required for extraction and cracking will be much higher.)

Natural gas is the fashionable alternative to liquid petroleum for the middle of the twenty- first century. However, it is interesting to note that the estimates of producible domestic gas that were made by energy companies and the US Geological Survey in the 1960s and 70s have undergone substantial reduction, probably due to the faulty estimation methodology noted above (Sterman et al. 1988). Gas reserves have declined since the 1970s. In 1972 the USGS estimated exploitable gas resources in the US at 2100 trillion cubic feet. By 1989 this had fallen eightfold to 263 trillion cubic feet. Meanwhile reserves fell from 293 trillion cubic feet in 1968 to 169 trillion feet in 1992, despite intensive exploration. The amount of domestic gas discovered per million feet of exploratory wells has declined for 50 years, despite improved technologies for identifying good places to drill. Production per well has declined from 500,000 cubic feet per day in 1972 to 185,000 cubic feet per day in 1992.

As with oil, the situation in the rest of the world lags several decades behind that in the US. For many years gas was a by-product of petroleum. As recently as 1986 about $5 \%$ of global gas produced (38\% for the Middle East) was still vented or flared [(Barns, Edmonds 1990), Figures 3.9 and 3.13]. This was due to lack of local markets or pipelines. However, the unrecovered proportion of the gas has been declining, partly due to increased capacity to transport gas in liquid form and partly due to increased consumption for petrochemical manufacturing (of methanol, MBTE and ammonia) in Saudi Arabia. Projections made in 1990 suggest a current venting/flaring fraction at 3\%. Gas wells are now being drilled for gas per se, independently of oil exploration. However, the geology is sufficiently similar to that for oil that the largest terrestrial and offshore gas fields have probably been discovered already. Global proven reserves as of 1991 amounted to 4000 trillion cubic feet, while mean estimates of undiscovered gas reserves were 5000 trillion cubic feet. Assuming normal growth in the gas market plus additional growth due to substitution for oil in some applications, this amounts to a 
century supply at zero growth rate, but only a 46 year supply at a $3 \%$ p.a. growth rate. Assuming the more likely pattern of peak output (and consumption) a few decades hence, followed by a gradual decline, the period of substitution of gas for petroleum must be limited to the first few decades of the coming century. After that, alternatives will probably be needed, not only for oil but also for natural gas.

As with oil, there are other potential, but expensive, sources of gas, notably gas dissolved under high pressure in very deep brines and 'frozen' gas (methane clathrates) on the edges of the continental shelves. However, for both conventional oil and conventional gas the double peak distribution pattern seems to fit the evidence fairly well.

Several points should be emphasized here. First, short and medium term hydrocarbon supply and prices may (and often do) reflect short term political or economic factors, unrelated to long term prospects. The mysterious increases in reserves during 1988-89 by the five OPEC countries illustrate the point. A more recent case in point is the reported Russian decision to maximize gas exports by the national gas company Gazprom (for hard currency) while depending on nuclear power as much as possible for domestic purposes, even to the extent of rehabilitating many old and unsafe nuclear plants of the Chernobyl type (Time Magazine, Sept. 18, 2000). This would be a massive change, since only $22 \%$ of 1996 Russian gas production was exported beyond the boundaries of the former USSR It would reduce domestic Russian production of carbon dioxide, thus adding to the potential value of carbon emissions permits that Russia will be able to sell in the carbon-trading market (advocated by the US) that was created by the Kyoto Accord (recently approved by Russia and now in effect.)

Incidentally, this decision will have adverse environmental impacts, not only in terms of likely radiation leaks ${ }^{\mathrm{x}}$ but also in terms of non-carbon greenhouse gases. Methane is 30-35 times more potent as a greenhouse gas than carbon dioxide. Hence gas leaks in production, transmission and distribution constitute one of the largest sources of methane in the atmosphere. Estimates vary widely. A Swiss study estimates that transmission losses in Europe average $0.02 \%$ for a pipeline of $1000 \mathrm{~km}$ in length, and that distribution losses average $0.07 \%$ in the high pressure component of the local distribution system (which consists of welded pipe) and $0.9 \%$ in the low pressure component (due to the use of mechanical fittings and joints) [(Dones et al. 1996) p. 34].This would imply overall system losses of somewhat less than $1 \%$, depending how much gas is taken from the low pressure grid (mainly by households.) ${ }^{\mathrm{xi}}$ This same study cites 1990 estimates of transmission losses in the Russian Federation ranging from 1\% to $10 \%$, with an assumed average of $2 \%$ (ibid), which is 100 times greater than the corresponding loss rate for Europe. The Russian gas pipelines are old, badly maintained and very leaky.

However there is some reason to believe that the $2 \%$ figure - an obvious attempt to be 'conservative' - is too low. In fact, the Russian gas monopoly, Gazprom, produced 565 billion cubic meters (bcm) of gas in 1996, of which only $501 \mathrm{bcm}$ were delivered to customers. Apparently $64 \mathrm{bcm}(11 \%)$ were lost, stolen, or consumed in transit. (The explanation favored by most experts is that the missing gas was stolen, mostly in the Ukraine). Just $75 \mathrm{bcm}$ arrived in Western Europe, of which $33 \mathrm{bcm}$ went to Germany (The Economist, Nov. 29, 1997). Evidently the quantity of Russian gas lost in transit is twice as great as the amount finally consumed in Germany! The quantity of gas 
consumed by turbo-pumps for pressurization is not specifically broken out, but for the US it is fairly close to $2 \%$ of total flow [(Ayres and Ayres 1998), p.76]. For Russia that figure might be doubled due to somewhat longer pipeline distances. That would still leave $7 \%$ (c. $40 \mathrm{bcm}$ ) as the loss by leakage and/or theft. It seems implausible that theft could account for anything like that much gas. Little, if anything, has been invested in the pipeline system since 1996, so it can be assumed that the loss rate is no lower, and probably even higher, than it was in 1996.

In any case, it seems likely that the distribution of hydrocarbons in the earth's crust is multi-modal, with small peaks for gas and liquid petroleum, and larger peaks for coal, heavy oils and shale. On the other hand, the latter two may be part of a single distribution. What seems very clear, however, is that liquid and gaseous hydrocarbons will be exhausted long before solids. The economic implication of this discussion is clear: the underlying assumption by most resource economists, that resources can always be found in larger quantities at lower grades, is simplistic and misleading.

\section{Other limits to substitution}

The near-impossibility of providing shelter and clothing without material inputs from natural or fossil sources has also been mentioned. It is true that there are many substitutes within the general category of building materials, and clothing materials, but there is no conceivable substitute for either category as a whole. Indeed, within some application subcategories, it is likely that we have already discovered and long-since adopted the optimum material. Thus, substitution by other materials is extremely unlikely. Window-glass is one example. Transparent plastics are superior in a few applications, but not in windows. Portland cement, concrete and bricks are quite likely others. (I do not exclude the possibility that concrete and bricks may be significantly improved by modifying the composition slightly, perhaps to reduce the weight or increase strength.)

Consider transportation. There is some potential for marginal substitution between transportation and communication (there is a vogue for 'telework' for instance). However since material goods are always going to be needed to some extent (as noted above) there will always be a need to move them from the places where they are produced to the places where they are used. There will also be a permanent need to remove worn out or useless materials from where they are used to places where they can be reprocessed or disposed of. Finally, all human experience to date suggests that people will continue to want (or need) to travel.

The possibility of teleportation (a la 'Star Trek') can be ruled out absolutely, if only on energy and information-theoretic grounds. To provide transportation services requires, as a minimum, vehicles (containment and propulsion) as well as communications for purposes of monitoring and controlling the system. Containment implies structural materials. These materials must combine strength, rigidity (for safety) and light weight. Passenger comfort adds further requirements. There are many combinations of known materials (metals, plastics, glass) that can be used, depending on the exact application. There is some possibility that composites based on carbon fiber, or light metals like magnesium or titanium, may find greater use than at present (although these materials are much more difficult to manufacture than conventional ones). Amory Lovins' 'hyper-car' design makes use of these possibilities (Lovins and 
Lovins 1995; Lovins et al 1996). But there is no possibility of reducing the mass of materials required for passenger/freight containment purposes to zero or near zero.

Propulsion capability is also an absolute requirement. Propulsion requires converting available energy (exergy) from some source into mechanical work to overcome friction from air, water or wheels. Of course one ancient possibility is selfpropulsion by the passenger (e.g. bicycle) or propulsion of a passive vehicle such as a cart or boat by an animal, flowing water, or wind. Some of these ancient methods may be revived, to a degree. However, in the future, there will certainly be a considerable requirement for propulsion by other more controllable means.

A propulsion system may be incorporated in the vehicle itself (by far the usual case) or - in the case of ground transportation only - it may be incorporated in an external guideway or track. There are two major subcategories of active (in vehicle) propulsion systems, depending on the nature of the energy conversion device. By far the most common type is heat engines, which convert the heat of combustion of some fuel into linear or rotary motion. There are several types of heat engines. ${ }^{\text {xii }}$ The other generic possibility for an active vehicle (on land only) is based on electric motors linked to wheels. Of course, the electric power can be generated centrally by a stationary power plant and transmitted to the vehicle via a conducting wire or track (as in an electric train or tram). This is an old technology that seems to have reached its inherent limits.

The other possibility is for electric power stored in an electrochemical battery in the vehicle, or derived from direct conversion of chemical energy (fuel) stored on board. The potential for rechargeable battery storage has been fairly thoroughly explored in recent years, and the nickel-metal-hydride (NiMH) system recently commercialized represents a substantial improvement over the old standard lead-acid system. On the other hand, future batteries based on other reversible electrochemical reactions are unlikely to be vastly superior to what is now available, either in terms of capacity or cost.

The fuel fora fuel cell may be hydrogen as such, or hydrogen obtained from a liquid, such as methanol or ethanol. Fuel cells operating at low temperatures and pressures based on hydrogen fuel and proton exchange membranes (PEM) appear to be on the verge of a significant breakthrough into automotive road transport, perhaps for buses. But so far the only practical means of large-scale hydrogen generation starts from natural gas. ${ }^{\text {xiii }}$ However hydrogen from direct electrolysis of water is a potentially feasible use of 'surplus' electricity either from intermittent sources (such as wind or solar PV) or from hydroelectric sources subject to variable loads. (This approach is currently being actively developed in Iceland). On board storage of hydrogen remains a problem for vehicles, although a number of possibilities are being explored.

There are a few other theoretical possibilities for in-vehicle energy storage. One is in the form of pressure, as in a compressed air tank. Another is in the form of mechanical energy stored as rotary motion of a high speed flywheel. A third is in the form of magnetic energy, stored in the form of a superconducting magnet. The first of these seems to be essentially dominated, in practice, by the second. High speed flywheels made from new composite materials are now a significant competitor to electrochemical batteries, at least in theory. However research in the area virtually stopped a few years ago because of safety considerations. A flywheel carrying enough energy to drive a vehicle a significant distance, but light enough to be practical, is 
essentially a bomb. Even a small disturbance (such as a 'fender-bender' collision) could result in destabilization and a violent release of energy.

An interesting new possibility that has received very little serious attention to date is for a passive vehicle to be propelled by traveling magnetic waves along a conducting track, probably aluminum. Magnetic levitation could be combined with this scheme. ${ }^{\text {xiv }}$ The very great advantage of such a scheme, in the long run, is that the vehicles would not have to carry the propulsion unit or the energy storage unit whatever it might be.

Obviously there are many possible combinations and permutations, especially for land transportation. (The choices for air and water transport are far more limited. In both cases there is no obvious competitor for internal combustion engines.) It is conceivable that in the course of the next century or so very substantial improvements in overall energy efficiency and materials intensity can be achieved by redesigning the system as a whole to take advantage of new (and old) possibilities. I am particularly intrigued by the potential use of passive vehicles on a conducting guideway for urban as well as inter-urban transport.

This possibility would seem to imply that there exists a significant opportunity for substituting man-made capital (infrastructures) for natural capital (fossil fuels). However, the new infrastructure on land would also be heavily dependant on conventional materials, derived from natural sources. Clearly, for the indefinitely foreseeable future, transportation cannot be de-linked from the use of physical materials, especially metals, and fuels.

I want to mention one last area where substitution possibilities are very limited, namely in electrical equipment, especially generators, household wiring, and motors. Motors are everywhere, and they all require copper wire in the form of windings. The same is true of generators. Copper is by far the best metal for this purpose (except for silver, which would be slightly better, but is a lot scarcer) and it has only one possible competitor, namely aluminum. Aluminum is only $60 \%$ as good a conductor - both electrical and thermal - as copper, which means that there is much more resistive heat generated in aluminum wire. For this reason, aluminum wire is now used only for very high voltage transmission lines, where the wire can simply be made bigger, but it is not used at all for household wiring, or in electrical equipment. Motors and generators could be designed to use aluminum wire, but to accommodate thicker wires they would have to be significantly larger - hence heavier - and they would run hotter and be less efficient. Substituting aluminum for copper is a theoretical possibility but would entail substantial economic losses. There is really no third possibility on the horizon. ${ }^{\mathrm{xv}}$

There are other areas of technology, notably communications and microelectronics, where new material combinations are emerging and where substitution is continuing. However the fact that substitution by ever-better alternatives is likely in some areas does not mean that it is likely (or even possible) in all areas.

\section{Conclusions}

History has exhibited technological solutions to many problems that appeared insurmountable, at first. It is tempting to think that this is "the age of substitutability", i.e. that new technologies can and will create viable substitutes for all kinds of natural 
capital, including materials, whenever and as needed. However the laws of nature are not so flexible. For most engineering problems there is actually a 'best' solution and, while the optimum solution for many problems has not yet been discovered, it does not follow that better or cheaper solutions remain in all cases. The example of illumination, mentioned earlier, also exemplifies the approach of final limits. There is no source of light superior to the light emitting diodes (LEDs) already discovered and soon to be widely utilized. LEDs convert $100 \%$ of the input electric energy into visible light. In fact, the major obstacle to mass production of these devices is physical scarcity of some of the component semiconductor metals, especially indium. It is easy to name a number of other application areas where the maximum possible performance is already known pretty accurately. Heat engine and fuel cell efficiency, combustion temperature, hardness of materials, tensile strength of fibers and strength at high temperature are a few examples. Electrochemical energy storage capacity per unit mass (i.e. storage battery weight, relevant to the laser pistol and the flying microbot) is another. In fact, there are relatively few areas now where ultimate limits cannot be foreseen if not yet closely approached. Artificial intelligence and biotechnology are the major exceptions.

The surprise, for me, in writing this paper is the extent to which the biosphere embodies a technology for which there is no known (or likely) alternative and which is truly essential to human survival. That is the technology for reducing carbon dioxide and recombining the carbon with hydrogen and other elements. So far as we now know, only photo-synthetic organisms can do that, and only with the help of organic compounds containing phosphorus. In principle, I suppose it might be possible to devise a multi-stage thermo-chemical process for obtaining - say - calcium carbide from calcium carbonate. From calcium carbide, in turn, the simplest hydrocarbon, namely acetylene, can be generated by adding water. From acetylene other hydrocarbons could, in principle, be created.

But, although I have searched the chemical engineering literature, I have not encountered any such process. If any reader knows of such a possibility I would be very grateful to learn about it.

\section{References}

Arndt, Richard A., L. David Roper. 1976. The metals and mineral fuels crisis: Facts and predictions. Blacksburg VA: University Publications.

Ayres, Robert U. 1999. The second law, the fourth law, recycling and limits to growth. Ecological Economics 29 (3):473-483.

Ayres, Robert U., Leslie W. Ayres. 1998. Accounting for resources 1: Economy-wide applications of mass-balance principles to materials and waste. Cheltenham, UK and Lyme MA: Edward Elgar. ISBN 1-85898-640-0.

Bachmann, H. G. 1960. The origin of ores. Scientific American:146-156.

Barns, David W., Jae A. Edmonds, 1990. An evaluation of the relationship between the production and use of energy and atmospheric methane emissions. Washington DC: United States Department of Energy, Office of Energy Reproach: April. TRO47:DOE/NBB-0088P

Berry, Gene D. 2004. Hydrogen Production. In Encyclopedia of Energy, Vol.2, edited by Cutler J. Cleveland. San Diego: Academic Press. 
Bianciardi, C., E. Tiezzi, Sergio Ulgiati. 1993. Complete recycling of matter in the framework of physics, biology, and ecological economics. Ecological Economics 8:1-5.

Campbell, Colin J. 1997. The coming oil crisis. Brentwood, UK: Multi-Science Publishing and Petroconsultants. ISBN 1-56973-222-1.

Campbell, Colin J., Jean H. Laherrère. 1998. The end of cheap oil. Scientific American 278 (3):60-65.

Committee on Mineral Resources and the Environment, 1975. Mineral resources and the environment. Washington DC: National Academy of Sciences- National Research Council:

Criswell, David R. 1991. Solar power system based on the moon. In Space Power: A 21st Century Option for Energy Supply to Earth, edited by Glaser and Davidson: Ellis Horwood Ltd.

2002. Energy prosperity within the 21st century and beyond: Options and the unique roles of the sun and the moon. In Innovative Energy Strategies for CO2 Stabilization, edited by Robert G. Watts. Cambridge, UK: Cambridge University Press. 0-521 80725 5.

Criswell, David R., Russell G. Thompson. 1996. Data envelopment analysis of space and terrestrial-based large-scale commercial power systems for earth: A prototype analysis of their relative economic advantages. Solar Energy 56 (1):119-131.

Daly, Herman E. 1997. Georgescu-Roegen versus Solow/Stiglitz. Ecological Economics 22 (3):261-266.

Dones, R., U. Gantner, S. Hirschberg, G. Doka, I. Knoepfel, 1996. Environmental inventories for future electricity supply systems for Switzerland. Villigen, Switzerland: Paul Scherrer Institut: February. PSI Bericht:96-07

Georgescu-Roegen, Nicholas. 1993. Thermodynamics and We, the humans. Paper read at Entropy and Bioeconomics: Proceedings of the first international conference of the E.A.B.S., at Milan.

Goeller, H., Alvin Weinberg. 1976. The age of substitutability. Science 191.

Hatfield, Craig Bond, 1997a. How long can oil supply grow? Golden CO: M. King Hubbert Center for Petroleum Supply Studies, Colorado School of Mines: October. Hubbert Center Newsletter:97/4

1997b. Oil back on the global agenda. Nature 387:121.

Hubbert, M. King. 1956. Nuclear energy and the fossil fuels: Drilling and production practice. American Petroleum Institute:7-25.

- 1969. Energy resources. In Resources and Man, edited by Cloud. San Francisco: W. H. Freeman and Company.

Kesler, Stephen E. 1994. Mineral resources, economics and the environment. New York: Macmillan Co.

Kolm, Henry H., Richard D. Thornton. 1972. The Magneplane: Guided electromagnetic flight". Paper read at 1972 Applied Superconductivity Conference, May 1-3, 1972.

Kolm, Henry H., Richard D. Thornton, Y. Iwasa, W.S. Brown. 1975. The Magneplane system. Cryogenics:377-384.

Landner, Lars, Lennart Lindestrom. 1999. Copper in society and in the environment; an account of the facts on fluxes, amounts and effects of copper in Sweden. Translated by Lars Landner. 2nd revised ed. Vasteras, Sweden: Swedish Environmental Research Group (MFG). ISBN 91-630-7932-1. 
Lovins, Amory B., Michael M. Brylawski, David R. Cramer, Timothy C. Moore, 1996. Hypercars: Materials, manufacturing, and policy implications. Snowmass CO: The Hypercar Center, Rocky Mountain Institute: March.

Lovins, Amory B., L. Hunter Lovins. 1995. Reinventing the wheels. Atlantic Monthly:75-86.

Masters, Charles D., David H. Root, William D. Ditetzman, 1983. Distribution and quantitative assessment of world crude-oil reserves and resources. Reston, VA: United States Geological Survey: Open-file Report:83-728

Mayumi, Kozo. 1993. Georgescu-Roegen's fourth law of thermodynamics, the modern energetic dogma and ecological salvation. In Trends in Ecological Physical Chemistry, edited by L. Bonati, U. Consentino, M. Lagsagni, G. Moro, D. Pitea and A. Schiraldi. Amsterdam: Elsevier.

McKelvey, V. E. 1960. Relation of reserves of the elements to their crustal abundances. American Journal of Science 258 (A):234-241.

Meadows, Donella H, Dennis L. Meadows, Jorgen Randers, William W. Behrens III. 1972. The limits to growth: A report for the Club of Rome's project on the predicament of mankind. New York: Universe Books.

Menard, H. William. 1981. Toward a rational strategy for oil exploration. Scientific American 244 (1):55-65.

Nordhaus, William D., 1994. Do real output and real wage measures capture reality? The history of lighting suggests not. New Haven CT: Cowles Foundation for Research in Economics at Yale University: September. Cowles Foundation Discussion Paper:1078

Pezzey, John, Michael A. Toman. 2002. Sustainability and its interpretations. Paper read at Scarcity and Growth in the New Millennium, November 18-19, 2002, at Washington D.C.

Skinner, Brian J. 1976a. Earth resources. Englewood Cliffs NJ: Prentice-Hall. 1976b. A second iron age ahead? American Scientist 64:258-269.

Solow, Robert M. 1974. The economics of resources or the resources of economics. American Economic Review 64.

1992. An almost practical step towards sustainability. Washington DC: Resources for the Future.

—. 1997. Reply: Georgescu-Roegen versus Solow/Stiglitz. Ecological Economics 22 (3):267-268.

Sparks, Jed P. 2004. Photosynthesis and Autotrophic Energy Flows. In Encyclopedia of Energy, Vol.5, edited by Cutler J. Cleveland. San Diego, CA: Academic Press. 0-12-176485-0.

Sterman, John D., George P. Richardson, Pal Davidsen. 1988. Modeling the estimation of petroleum resources in the United States. Technological Forecasting and Social Change 33:219-249.

Subak, Susan, Paul Raskin, David von Hippel, 1992. National greenhouse gas accounts: Current anthropogenic sources and sinks. Boston: Stockholm Environmental Institute: January.

United States Geological Survey World Energy Assessment Team, 2000. US Geological Survey world petroleum assessment: description and results. Reston VA: United States Geological Survey: Digital Data Series:DDS-60.

i. The case for infinite substitutability was also strongly supported by some physicists, at the time, notably in a 1976 article (Goeller and Weinberg 1976) called "The Age of Substitutability" in Science (later reprinted in the Journal of Economic Literature). The article was essentially a case study of mercury, noting many of the historical uses of the metal and the subsequent substitution 
by other materials or techniques. However, the mercury story - however fascinating - is hardly a proof that good substitutes can always be found for all materials regardless of function. In fact mercury has some unique properties (including the fact that it is a liquid at room temperature and its ability to amalgamate with gold and silver) that make it impossible to substitute for in some applications.

ii. This does not apply to the Ross (and several other) ice shelves, which rest on the seabed and which might break up and melt much more quickly, if global warming continues. There is already some evidence of cracking and possible breakup.

iii. To live on a barren planet - like the moon - without a pre-existing oxygen atmosphere or hydrocarbons we humans would have to live inside small airtight domes with devices to extract oxygen from silicon or aluminum oxides, probably electrolytically.

iv. A PV-based manufacturing system on earth would also be limited by the diurnal cycle and the variability of cloud cover. It has been argued that a self-reproducing PV system on the moon would be about four times more efficient, and that the surplus energy produced there could be sent to earth by means of microwave beams with little loss and no danger to people (or wildlife). See, especially, (Criswell 1991; Criswell, Thompson 1996; Criswell 2002)

v. There is an unproved theory that some natural gas might have originated from the bombardment of the earth by protons (hydrogen ions) from the sun, although the mechanism of methane creation remains unclear.

vi. The common carboxylation (carbon fixation) process is a 13-step cycle involving 11 enzymes, starting with the most important enzyme, in nature, known as ribulose bisphosphate (RuBP). ATP and NADPH are required to regenerate the RuBP. They, themselves are regenerated by other ('dark') reactions. The fixation of a single CO2 molecule consumes no less than 3 ATP and 2 NADPH molecules (Sparks 2004).

vii. The reason appears to be that biological recycling processes necessarily involve anaerobic reduction yielding gaseous compounds, such as methane and carbon dioxide, ammonia and nitrous oxide, hydrogen sulfide, dimethyl sulfide (DMS), carbonyl sulfide (COS) and sulfur dioxide. These gases redistribute the elements in question and make them available. But the only gaseous compound of phosphorus is phosphine (H3P) which is extremely toxic to higher animals. If there existed a significant biological process to recycle phosphorus, by producing and dispersing phosphine, it is hard to imagine how higher animals could have evolved. (Hydrogen sulfide and ammonia are also toxic, but they oxidize quickly to other gasous compounds, whereas phosphorus oxides are not volatile.)

viii. Apparently the bimodal distribution is still regarded by most geologists as speculation. It is true that there is no direct evidence of bimodality. However, this is not a serious objection, inasmuch as there is equally no direct evidence for the McKelvey hypothesis of single modality. On the other hand, if copper, lead and zinc were distributed according to the McKelvey rule, the total quantities in the earth's crust must be hundreds or thousands of times greater than the accepted crustal abundance.

ix. A somewhat simpler methodology, known as production history forecasting, involves predicting the future shape of the theoretical production curve from the historical data alone. The 'best fit' is then used to predict future production history. This method was systematically applied to all mineral, metal and fuel resources, using U.S. and global data available up to the mid 1970s (Arndt, Roper 1976). The method does not make use of the additional data (on rates of discovery, proved reserves and so on) used by Hubbert. It is interesting to note that Arndt \& Roper's curve-fitting method, using data through 1974, predicted that the peak year would occur in 1984, whereas in fact it had already occurred in 1970. For global production, they predicted a peak in 2034, which now appears very unlikely.

x. According to a report prepared for the Russian government (and evidently leaked), during the last fifty years 384 reactor accidents have occurred in Russia, that released radiation, resulting in 58 deaths and 214 cases of acute radiation poisoning. In contrast, there has only been one reactor accident that released radiation in France, with no deaths (Time Magazine Sept. 18, 2000, p.43). 
xi. A US study sponsored by the DOE concluded that 'unaccounted for' natural gas losses, calculated as the difference between system inputs and delivered outputs, with an allowance for gas used to operate compressors, amount to $2 \%$ on average (Barns, Edmonds 1990). This figure is consistent with a weighted average of reports from individual distributors (ibid). A later study by the Stockholm Environment Institute arrived at a slightly (17\%) lower estimate, but without specifying the methodology (Subak, Raskin, von Hippel 1992). The small difference between the US and Europe is probably due to the fact that the US distribution system is, on average, somewhat older.

xii. Heat engines are divided into two major categories depending on whether the work is done by the combustion products themselves (internal combustion) or by a separate 'working fluid' that is recycled (external combustion). Internal combustion engines, in turn, are subdivided along two dimensions. One dimension is whether the motion is linear (piston or jet) or rotary (e.g. turbine). The other is whether the combustion is ignited by compression (diesel) or requires a spark (Otto cycle). External combustion - e.g. Rankine (steam) or Stirling - engines are also subdivided between piston types and rotary types (turbines), although only the latter survives in practice. An external combustion jet engine is not possible.

xiii. Thermal decomposition of water at high temperatures is impractical below $2500 \mathrm{C}$ and above that temperature the hydrogen molecules also decompose, resulting in a mix of atomic hydrogen, atomic oxygen and hydroxyl radicals. Two stage thermo-chemical processes with regeneration of an intermediate are feasible but none appear to be attractive (Berry 2004). One three stage process, the sulfur-iodine system developed by General Atomic, appears to be attractive, based on laboratory work (ibid). But it would require high pressures and a continuous high temperature source of heat, such as an advanced high temperature helium-cooled nuclear reactor, that could also be used to generate electric power directly. A four stage thermo-chemical process involving lower temperatures has been developed to the pilot stage at the University of Tokyo, known as UT-3 (ibid). It can be operated at sub-atmospheric pressures, on a batch basis, but scale-up problems remain.

xiv. The system in question has been described, patented and demonstrated on a small scale (Kolm, Thornton 1972; Kolm, Thornton, Iwasa, Brown 1975). However, the US government (unlike Germany and Japan) has never invested in magnetic levitation technology so the Magneplane system has never been scaled up to the next level (which would cost quite a few millions of dollars).

xv. I should mention the outside possibility that room temperature superconductors could become a significant competitor for some applications of copper. However, no super-conductor has yet come close to operating at room temperatures, and all of the best examples discovered to date are ceramics (oxides) involving several different rare-earth elements. Granted, rare earths are not particularly rare, but ceramic conductors are exceedingly difficult to manufacture and probably always will be. At this point in time, most experts have become rather skeptical of the possibility. Another remote possibility that has emerged very recently, is the use of bundles of carbon nano-tubes in place of copper wires. However the manufacturing problems would be even more daunting and (as noted previously) pure carbon for any such purpose (like carbon fibers) would have to be obtained from hydrocarbons. 